\title{
CURSOS ONLINE DE PALEOGRAFÍA: HERENCIAS, LIMITACIONES, LOGROS Y PROPUESTAS
}

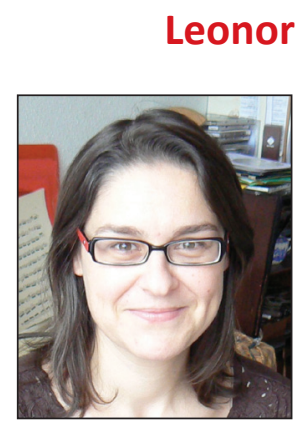

Zozaya

Leonor Zozaya es doctora Europeus en historia por la Universidad Complutense de Madrid (UCM). Obtuvo prestigiosos contratos y becas vinculados al CSIC (FPU, I3P, etc.) y a la UCM, donde fue profesora de ciencias y técnicas historiográficas (2006-2011). Ha desempeñado labores archivísticas en varios archivos $(A H N, B N E)$. Actualmente es becaria post-doctoral en el CHSC de la Universidade de Coimbra (Portugal). Completó su formación en el Saint John's College (Cambridge University, Inglaterra) y en la École des Hautes Études en Sciences Sociales (CNRS, París). Ha publicado más de cincuenta investigaciones científicas, como su libro De papeles, escribanías y archivos (Madrid, CSIC, 2011). Miembro de diversos equipos y proyectos de investigación, ha participado en numerosos congresos en calidad de ponente, comunicante y personal científico-técnico, como el celebrado en Tsinghua University (Pekín) con AHLiST. Fue vocal del comité técnico en la revista Documenta \& instrumenta.

http://orcid.org/0000-0002-6256-1888

Universidade de Coimbra, Faculdade de Letras, Centro de História da Sociedade e da Cultura (CHSC) Largo da Porta Férrea, 3000-447 Coimbra, Portugal leonorzozaya@gmail.com

\section{Resumen}

Se analizan nueve cursos interactivos dedicados a la docencia de paleografía elemental, o de lectura, en su modalidad digital de libre acceso en internet. Se presta atención especial a sus logros, así como a las herencias del sistema docente anterior. Se explica la terminología elemental de los conceptos manejados. Se resumen las características del sistema de aprendizaje de paleografía tradicional, pues en él se basan numerosas fórmulas telemáticas actuales. Esta retrospectiva tiene la finalidad de determinar qué méritos son atribuibles al sistema anterior. Finalmente se discuten las ventajas y los inconvenientes de los nuevos sistemas de aprendizaje.

\section{Palabras clave}

Docencia, Aprendizaje, Auto-formación, Cursos online, Cursos digitales, Software, Paleografía, Ludificación, Digital, Interactivo, Telemático, Online, Multimedia, Internet, TIC, Tecnologías de la Información y la Comunicación.

\section{Title: Online paleography courses: heirlooms, constraints, achievements and proposals}

\section{Abstract}

Nine digital courses on deciphering and reading palaeography are analysed. The study focuses on their successes, taking into account the borrowings inherited from the previous educational materials. The article explains the main terminology, then summarizes the characteristics of the traditional system of learning palaeography upon which the current online systems are based. The aim of this retrospective analysis is to determine which achievements can be attributed to the previous system. Finally, the advantages and disadvantages of the new learning systems are discussed.

\section{Keywords}

Teaching, Learning, Self-study, Palaeography, Paleography, Digital, Online courses, Software, Gamification, Interactive, Telematics, Multimedia, Internet, Information and communication technologies (ICT).

Zozaya, Leonor (2014). "Cursos online de paleografía: herencias, limitaciones, logros y propuestas". El profesional de la información, septiembre-octubre, v. 23, n. 5, pp. 475-484.

http://dx.doi.org/10.3145/epi.2014.sep.04

\section{Introducción sobre los conceptos utilizados}

Para evitar confusiones referentes a los conceptos que aquí se manejan, se ofrece una breve explicación sobre los siguientes términos: paleografía, paleografía elemental y cursos interactivos digitales con finalidad docente.
Paleografía es un vocablo de origen griego cuya etimología sig-

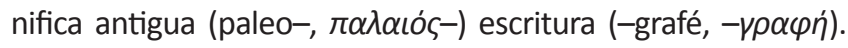
Dicha disciplina se ocupa del conocimiento de la escritura antigua. Éste término de significado tan amplio es difuso, pero generalmente alude a un sistema gráfico arcaico que ha caído en desuso (figura 1), que requiere aprender a descifrar su lectura. 




Figura 1. Fragmento de un documento del año 1622 (protocolo Zozaya, archivo particular)

La paleografía tiene diversas finalidades y especialidades. Una es la paleografía elemental, aunque también recibe otras denominaciones, por ejemplo, paleografía práctica o de lectura. Consiste en leer signos gráficos antiguos para transcribir documentos. Descifrarlos suele presentar numerosas dificultades. Por ello, se sirve de sistemas para aprender a leerlos.

Existen numerosos métodos educativos para estudiar paleografía elemental. Este artículo se centra en los cursos y ejercicios interactivos online, de libre acceso en internet. Esas propuestas nacieron gracias a la aplicación de las tecnologías de la información y la comunicación (TIC) en la enseñanza.

Esos cursos interactivos son novedosos, es innegable. Pero parte de los ejercicios paleográficos que proponen ya se han practicado antes de la denominada era digital. Por ello es necesario señalar los préstamos que ha tomado de la docencia tradicional. Acaso esto parezca obvio, pero la experiencia demuestra que hay generaciones de alumnos que creen que todo lo que consta en formato telemático es mérito moderno, cuando no es siempre así.

Los sistemas tradicionales para enseñar paleografía elemental conviven con los avances más punteros de la era digital

Estas explicaciones advierten, a quien tenga intereses diferentes, de que aquí no se tratarán otros temas. Se omitirán cuestiones referentes a los métodos de reconocimiento automático de manuscritos, tratados en congresos especializados como el ciclo International conference on frontiers in handwriting recognition. Se prescinde igualmente de comentarios sobre los materiales docentes de la asignatura paleográfica (para lo que remito a Ramírez-Sánchez, 2005a). Tampoco hay en este artículo listas de facsímiles con enlaces de libre acceso en internet. Estos ya se recogen en diversos espacios virtuales, por ejemplo en el blog de Paleografía y ciencias afines. Allí también se anuncian cursos de paleografía impartidos online, pero estos básicamente usan el soporte digital como un medio de educación a distancia, no como un fin, por lo que también se excluyen. Para completar otros conocimientos concernientes a proyectos digitales de paleografía se recomienda consultar Conscriptio. El blog de las ciencias y técnicas historiográficas.

http://paleografia.hypotheses.org

http://conscriptio.blogspot.com.es

\section{Antecedentes: métodos docentes de paleografía elemental previos a la era digital}

Los sistemas tradicionales para enseñar paleografía elemental no han perecido. Conviven y convivirán con los avances más punteros de la era digital. Ello se debe a que en numerosos casos la metodología clásica de docencia ha sido transportada directamente al lenguaje informático. Así, básicamente ha cambiado el medio y el soporte, no el método de enseñanza.

Esa traslación es lógica, pues los sistemas telemáticos están diseñados con el asesoramiento de paleógrafos cuya formación ha seguido los métodos tradicionales. Por ello es importante plantear qué aportaron los sistemas clásicos y qué aportan los nuevos, para ponderar sus méritos.

Los métodos docentes tradicionales de paleografía elemental se basan en leer; el aprendiz aprende descifrando facsímiles antiguos. La siguiente fase varía según se corrija esa lectura, lo cual depende del sistema de aprendizaje. Si se trata de docencia presencial, el profesor intervendrá corrigiendo la transcripción. Si no hay docente, el aprendiz irá probando con la táctica del ensayo-error, cotejando su lectura con la transcripción.

Para practicar la lectura paleográfica en España, los sistemas descritos acostumbran a utilizar los típicos manuales (Millares-Carlo, 1983; Riesco-Terrero et al., 1995, más otros citados al hilo del discurso). El método común a todos ellos se basa en adjuntar un facsímil y su transcripción. Además, algunos añaden elementos metodológicos útiles; por ejemplo, normas de transcripción (Arribas, 1965, pp. 7-20; Cortés-Alonso, 1986, pp. 97-99), o sugerencias para facilitar la lectura (Uned, 2005, pp. 31-32; Pérez-Herrero; Rivero-Suárez, 2006, pp. 175-180). También se estila incluir alfabetos, tablas de nexos y abreviaturas (figura 2). Algunos



Figura 2. Alfabeto de caracteres antiguos (Zozaya, 2012b, p. 369). 
de ellos agregan teoría sobre la historia de la escritura, enriquecedora pero prescindible para aprender a leer. Según se verá, la mayoría de los cursos de paleografía telemáticos los agregan también.

Los métodos de aprendizaje basados en la docencia presencial y en ejercitarse con un manual han proporcionado diferentes resultados. En teoría son válidos para lograr que el aprendiz sea competente leyendo paleografía, pues muchos lo han conseguido así. Sin embargo, los mismos sistemas no han sido efectivos para otra cantidad significativa de alumnos. En la práctica pueden generar tedio, desorientación e incertidumbre, máxime cuando la docencia se imparte en aulas masificadas (Zozaya, 2013a).

Para mejorar el sistema docente tradicional de paleografía se han ingeniado cursos interactivos como los que se tratan a continuación.

\section{Cursos para aprender paleografía elemental en internet}

Actualmente las agencias de acreditación docente promueven que el profesorado universitario emplee las TIC en la enseñanza, descuidando en ocasiones cómo se aplican. Delgado-Aguiar, Martín-Rodríguez y Ramírez-Sánchez (2005, p. 268) han señalado acertadamente que es habitual que la telemática aplicada a la docencia se limite a transmitir el conocimiento perpetuando el modelo anterior, a la antigua usanza. Sin embargo, el uso de las TIC requiere un nuevo rumbo que rompa los viejos moldes.

En la disciplina paleográfica, ¿ha ocurrido lo mismo? La respuesta depende del caso que se examine. Peter Stokes (2010, p. 230) afirmaba que la era digital está transformando la enseñanza de las humanidades, que incluso ha penetrado en campos tan tradicionales como la paleografía. Esa entrada, insisto, no significa que siempre aporte algo nuevo ni que haya logrado obtener rendimiento del lenguaje telemático. Por ello es necesario revisar las herencias del sistema anterior y las invenciones propias de la era digital.

Es oportuno mencionar que las herramientas y los programas informáticos que ofrecen estos cursos proceden de diversos orígenes. En algunas ocasiones han sido creados por paleógrafos, y, en otros, por programadores informáticos, y después reutilizados por paleógrafos que han aplicado las TIC en la innovación docente. Baste ofrecer un par de casos:

- Por un lado, la herramienta informática Hot potatoes sirve para hacer ejercicios interactivos multimedia de autocorrección. Fue creada en la University of Victoria (Canadá), y ya ha sido aplicada en el curso de paleografía Scriptorium (epígrafe 3.9).

- Por otro lado, se da la situación de alguien que crea un software ingeniado ex profeso para hacer ejercicios interactivos de transcripción paleográfica. Ese fue el caso del programa Paleography, de licencia libre en la web Image markup tool. Ofrece un conjunto de herramientas para crear ejercicios, aplicado ya al menos en dos plataformas (epígrafes 3.6 y 3.7 ).

Para sopesar qué ofrecen los cursos interactivos de paleografía digital procede repasar algunos de los más innovado- res. Este compendio suma sólo nueve, así que no es exhaustivo. En la selección han influido varios aspectos, a parte de la limitación de espacio. Buscando los más punteros, se han dejado de lado propuestas que en el año 1997 fueron tan novedosas como la del Cours d'initiation à la paléographie médiévale et moderne, ya desfasada debido a la vertiginosa evolución de la tecnología.

Otro criterio para seleccionar estos cursos ha sido el idioma. Por ahora no hay cursos en español, aunque Script tutorials (Brigham Young University) prometa traducir sus ejercicios multimedia. Por ello, aquí se ha optado por los ejercicios más nítidos, en lenguas que en teoría son familiares para los hispanoparlantes. También se han elegido cursos idiomáticamente versátiles, por así denominar a algunos que se presentan en una lengua (inglés, francés, catalán) la cual básicamente es un medio para acceder a los facsímiles escritos en otra (latín, español, italiano). Ello implica que permiten practicar paleografía sin saber el idioma inicial. Pensando en ello, y en facilitar el seguimiento de esta disertación, se citarán entre paréntesis ciertos extranjerismos donde hay que hacer clic (ejemplo: en "hint", que significa pista o sugerencia) para acceder fácilmente a los ejercicios. La presentación de los cursos sigue este orden de idiomas: inglés, francés y catalán.

\subsection{Scottish handwriting}

Esta web está patrocinada por los archivos nacionales de Escocia. Ha sido realizada por investigadores y profesores usuarios de sus archivos. Ofrece un curso para aprender a leer la letra de la Edad moderna (del año 1500 al 1700) redactada por escribanos del país.

Lo que aquí más interesa son los ejercicios del curso (en tutorials). Tienen tests con la mayoría del texto transcrito, salvo ciertas palabras que ha de descubrir el aprendiz (figura 3). Este método práctico permite aprender fácilmente a leer nuevas grafías casi de forma inconsciente. Ofrecer los primeros renglones del facsímil transcritos no es una invención telemática, ya se ha hecho incluso en exámenes en papel. La



Figura 3. Ejercicio de lectura paleográfica (curso Scottish handwriting) http://dwriting.com/dunL1T.asp 


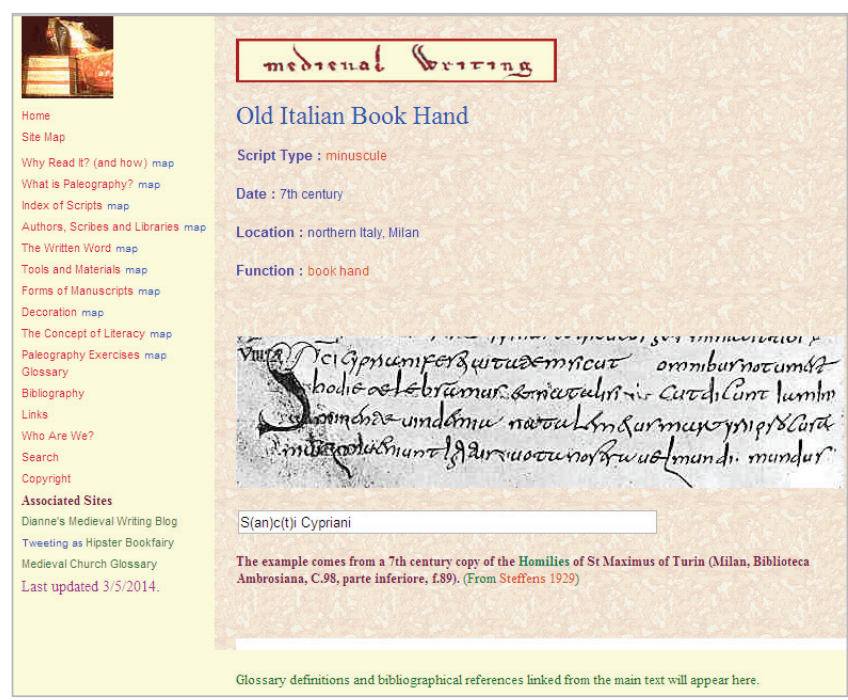

Figura 4. Colocando el cursor sobre la ese mayúscula del facsímil, en la casilla inferior aparece la frase Sancti Cypriani donde se incluye dicha letra (Medieval writing).

http://medievalwriting.50megs.com/writing.htm

novedad digital acaso radique en que la corrección es inmediata, que por añadidura regala una plétora de pruebas a la libre disposición del alumnado.

El curso es muy completo, pues además contiene otras informaciones y materiales de apoyo muy útiles (que tampoco son invento telemático). Adjunta por ejemplo un glosario, teoría paleográfica, alfabetos con imágenes de cada letra, estudios sobre numerales y cronología. Además proporciona nuevos ejercicios semanalmente; también, por ejemplo, consejos para mejorar el rendimiento de la lectura paleográfica. Da una recomendación original, en el sentido de que pocos programas digitales la proponen: consiste en pedir al alumnado que escriba la frase sic braw secretarie hand, que incluye las letras más problemáticas de leer. La práctica de escribir en caracteres antiguos es crucial, pues si se conoce cómo se formó la letra es más fácil aprender a reconocerla. Este procedimiento mimético es antiguo, y su aplicación cuenta con numerosas variantes, como la recomendación de hacer alfabetos. Además, recuerda a los

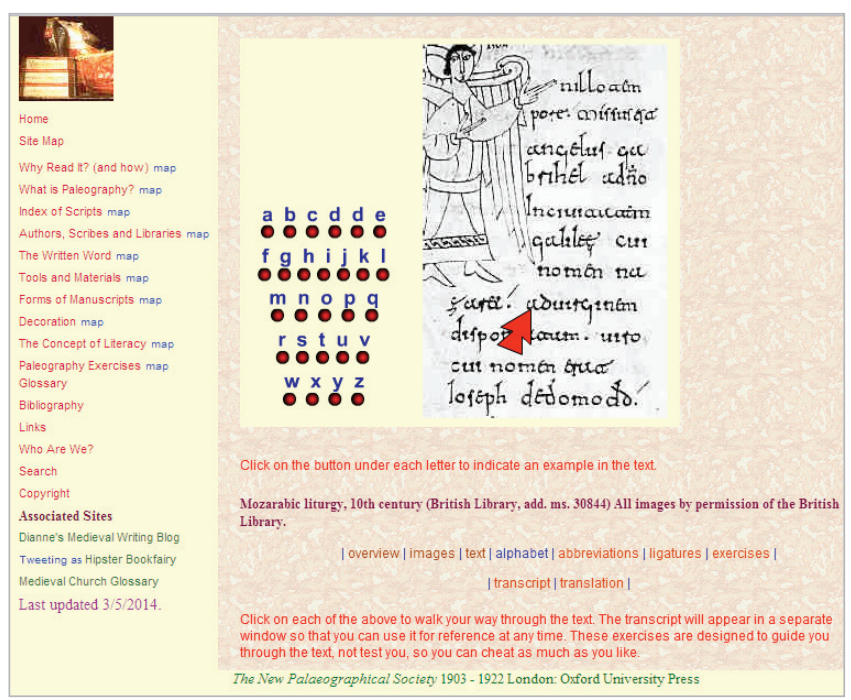

Figura 5. Ejercicios para reconocer letras y abreviaturas del curso Medieval writing

http://medievalwriting.50megs.com/writing.htm

ejercicios escolares medievales para aprender a escribir, que redactaban frases que contuviesen todas las letras del abecedario (Sánchez-Prieto, 2010, p. 16).

\subsection{Medieval writing}

Se trata de una iniciativa privada procedente de Australia, del matrimonio de profesores Diane y John Tillotson. Anuncian un método para aprender sólo paleografía medieval, pero realmente ofrecen ejercicios con documentos y epígrafes cuyas cronologías abarcan desde el siglo IV hasta el XVI. Al igual que otros sistemas, incluye información relativa a la historia de la escritura y la lectura, así como la evolución de cada letra en diferentes ciclos escriturarios. Del mismo modo explica las particularidades complejas de ciertas letras y nexos. Todo esto también se ha dado en los manuales tradicionales.

El mérito de este sistema radica en incluir ejercicios de paleografía novedosos. También son numerosos, por lo que sólo se reseñan aquí los más intuitivos. Una de las pruebas proporciona varios facsímiles (en index of scripts, eligiendo cualquiera de las listas). Se elige uno, $y$, al situar el cursor en cualquiera de sus letras, aparece la transcripción de la palabra o de la frase donde se inserta la citada letra (figura 4). Tiene el inconveniente de que no transcribe las letras por separado, lo cual puede confundir al aprendiz respecto a qué grafía antigua se corresponde con el conjunto de letras transcritas. Este problema también se daba en los manuales tradicionales.

Otro logro de este curso se halla en la sección de ejercicios (en paleography exercises, figura 5). Colocando el cursor sobre una letra

Figura 6. Ejercicios de paleografía, facsímil con su transcripción (Medieval writing). http://medievalwriting.50megs.com/writing.htm

http://medievalwriting.50megs.com/exercises/ramsay/transcript.htm 
de imprenta actual, un vector rojo se desplaza hasta la representación gráfica del carácter antiguo con el que se corresponde. Existe además la misma aplicación para ver abreviaturas (en abbreviations).

De la misma forma, acudiendo a otros facsímiles para practicar con ejercicios de paleografía, buscando la transcripción (en transcript, línea inferior derecha, figura 6), ésta aparece inmediatamente.

\subsection{English handwriting}

Este curso ha sido realizado voluntariamente por estudiantes, académicos y técnicos de la University of Cambridge (Inglaterra). Versa sobre paleografía de los años 1500 a 1700.

Su gran acierto telemático se halla en sus ejercicios interactivos (en course lessons). Permiten ver a la vez el facsímil más dos ventanas inferiores (figura 7):

- la izquierda permite transcribirlo (en model transcription), con la posibilidad de acceder al pdf de la solución;

- la derecha (en about this hand) informa del tipo de letra, y adjunta la bibliografía pertinente.

Además, ofrece materiales complementarios, por ejemplo alfabetos, glosario, facsímiles, estudio histórico, pautas de cronología, convenciones internacionales de transcripción, bibliografía, recursos en internet, enlaces a otros cursos de paleografía, e incluso un manual de escribanos del año 1618 digitalizado, aportación inusitada. Aunque todo esto era accesible mediante los sistemas docentes anteriores, aquí se aporta mucha información reunida, cuyo volumen no ocupa lugar.

\subsection{Spanish paleography}

Se trata de una iniciativa del Dominican Studies Institute (Nueva York) para aprender paleografía hispánica. Aunque los documentos antiguos están escritos en español, se ofrece en inglés tanto el curso como las instrucciones de uso.

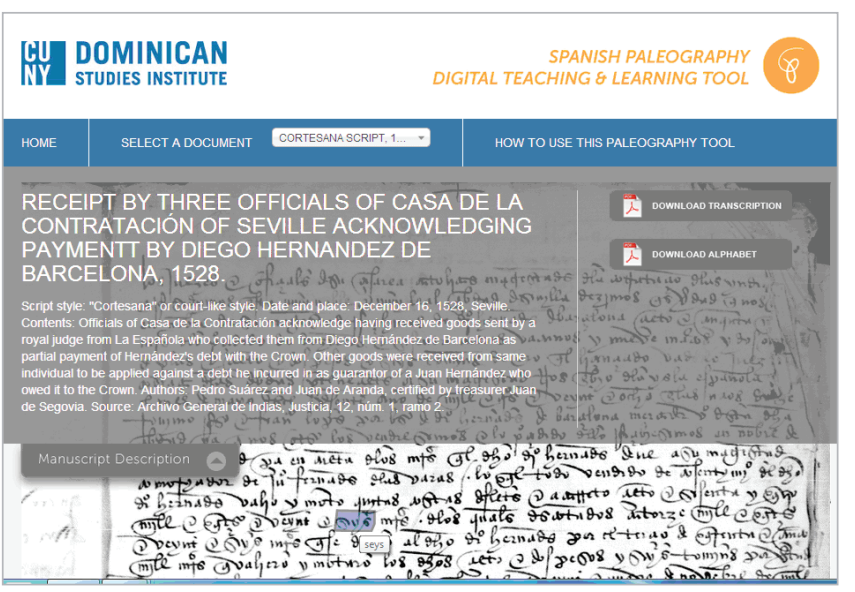

Figura 8. Palabra destacada y transcrita al colocar el cursor sobre una grafía (Spanish paleography).

http://spanishpaleographytool.org/dsi_documents/agi-justicia-12-num1ramo2-jueces-de-la-contratacion-01
Pero es tan nítida que se le puede sacar rendimiento sin ser angloparlante.

Su aportación más original radica en la sencillez de la presentación y la inmediatez de sus resultados. Los facsímiles se localizan fácilmente (en select a document). Si se coloca el cursor sobre una letra, automáticamente se destaca la palabra a la que pertenece, al quedar rodeada por un perímetro azul (figura 8). A la par, aparece la transcripción (de la palabra, no de cada letra). Haciendo clic en el mismo sitio, asoma un recuadro con más información (alfabeto, abreviaturas, etcétera).

Con cada facsímil adjunta en pdf la transcripción y un alfabeto (figura 9), que se ve a la par que el documento antiguo. Aunar en la misma plana lámina y transcripción es muy práctico; pero no es nuevo (véase por ejemplo CortésAlonso, 1986).

\subsection{Palaeography \& Latin palaeography}

The National Archives del Reino Unido han creado uno de los programas docentes más completos. También destaca por la riqueza de sus materiales complementarios. Ofrecen dos cursos (en reading old documents):

- Latin palaeography, con facsímiles en latín medieval;

- Palaeography, con repertorios documentales en inglés de época posterior.

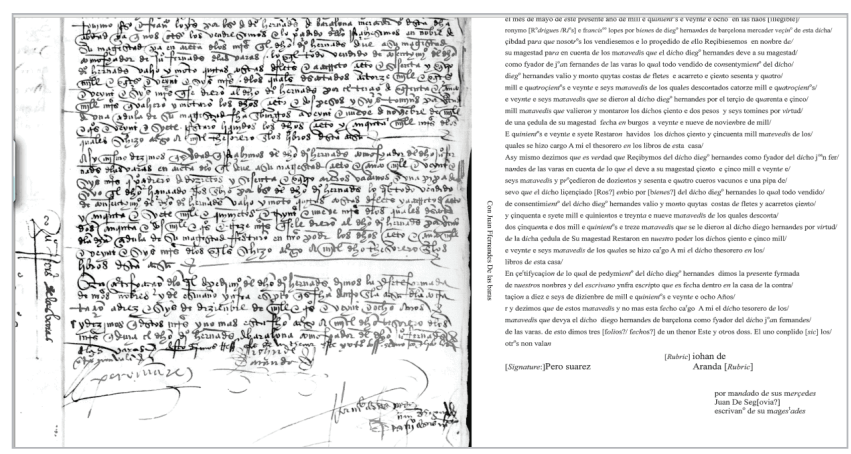

Figura 9. Descarga de una transcripción en el curso Spanish paleography. http://spanishpaleographytool.org/wp-content/uploads/2013/06/agijusticia-12-num1-ramo2-jueces-de-la-contratacion-01-double.pdf 


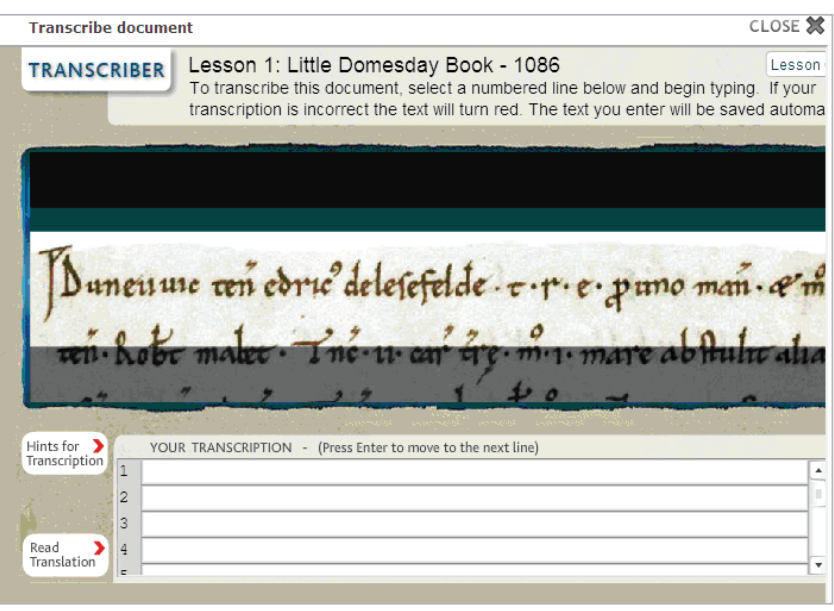

Figura 10. Imagen del curso Latin palaeography

http://www.nationalarchives.gov.uk/latinpalaeography

\section{Latin palaeography}

Su curso de paleografía latina (en Latin palaeography) abarca facsímiles del año 1086 al 1500 . Sólo ofrece documentos en latín, lengua sobre la que además brinda dos seminarios online. También facilita información y materiales de apoyo similares a los de otros cursos (con abreviaturas, alfabetos, glosario, bibliografía y normas de transcripción, necesarias para aplicar en las pruebas). Igualmente proporciona facsímiles con sus transcripciones y traducciones.

El apartado que aquí más interesa alberga diversos tipos de lecciones (en lessons). Allí, al dirigir el cursor hacia un ejercicio para ir a transcribir el facsímil (en transcribe document), aparece un fragmento destacando cada renglón (figura 10). Para transcribir, tiene un espacio rayado para rellenar cada línea. Se pueden pedir pistas (en hints), que despejan dudas relativas a los aspectos gráficos del documento.

Igualmente incluye otra actividad fácil y amena para aprender a leer las abreviaturas (en abbreviation matching activity). Éstas se muestran en caracteres actuales de imprenta, y hay que vincularlas a su correspondiente facsímil.

También cuenta con un ejercicio interactivo original para mostrar los alfabetos de cada facsímil (en explore letters). Se ve representada una máquina mecanográfica (figura 11) en la que, presionando cada tecla, aparece la letra con su correspondiente grafía antigua. Esto es muy didáctico, capaz de motivar más al alumno que los clásicos alfabetos estáticos.

\section{Palaeography}

Sus facsímiles, escritos en inglés, abarcan desde el año 1500 al 1800. Accediendo a los ejercicios interactivos (en interactive tutorial) se



Figura 11. Máquina para ver las letras del alfabeto seleccionadas (Latin palaeography)

http://www.nationalarchives.gov.uk/latinpalaeography

presentan los textos ordenados según su dificultad. Al elegir uno (figura 12), el sistema permite transcribir por renglones. Ofrece siempre la solución de la primera línea, acierto didáctico ya comentado. Tras completar la transcripción de cada renglón, permite evaluar (en submit), y automáticamente aparece una estadística de las palabras acertadas y falladas. A diferencia del curso anterior, este apartado ofrece un alfabeto estático. Suma igualmente el resto de materiales como el glosario, el facsímil o la transcripción completa.

El sistema cuenta también con un juego (en game, ducking stool) representado por una xilografía que muestra una antigua forma anglosajona de castigo público llamado ducking stool ("esquivando el taburete"). Éste consistía en atar una persona a una silla y sumergirle en el agua. El juego que proponen versa sobre el siguiente supuesto del siglo XVII: una mujer ha sido acusada de un crimen, y sólo se la libera transcribiendo correctamente los fragmentos facsimilares que van apareciendo. Si se falla, mientras ella cae al agua

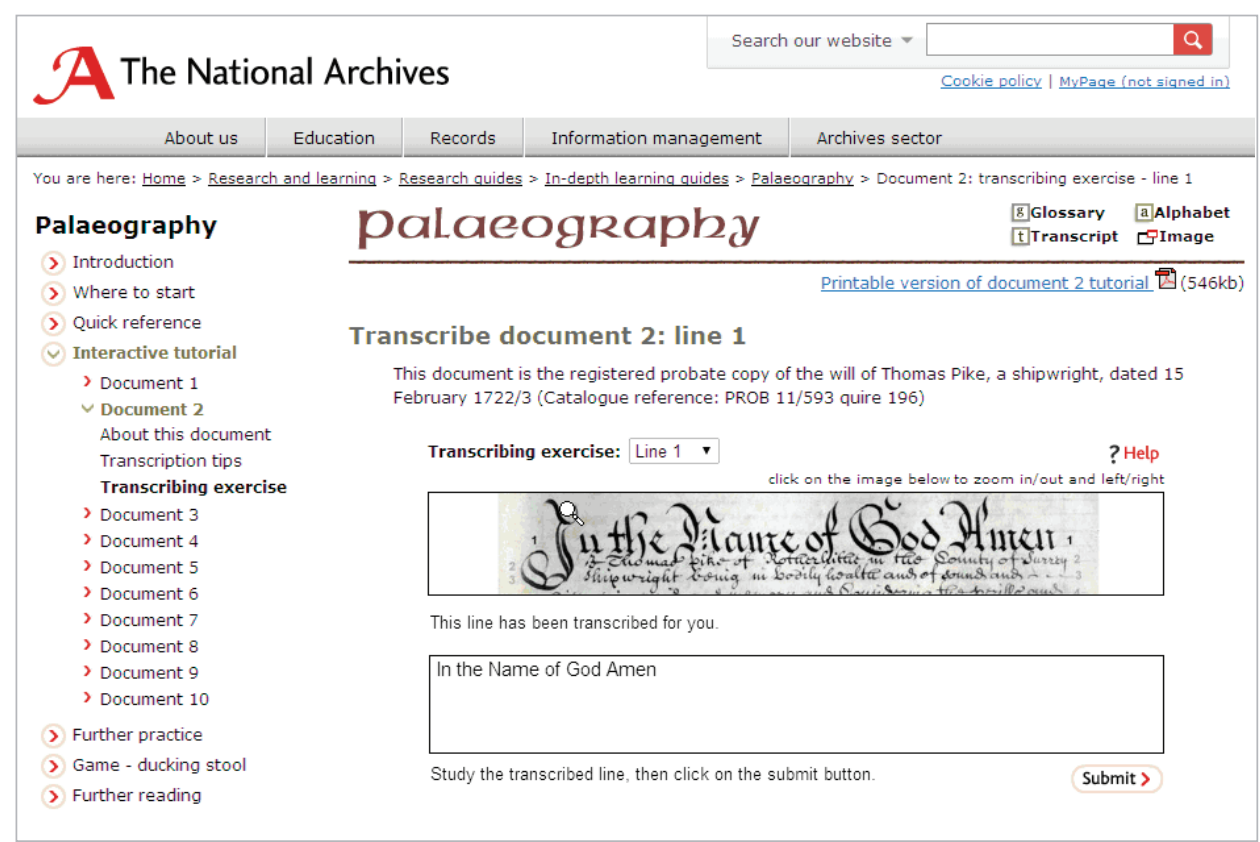

Figura 12. Primer renglón con la transcripción resuelta del curso Palaeography http://www.nationalarchives.gov.uk/palaeography/doc2/doc2_01.htm 
un mensaje muestra la solución correcta. Pese a la selección cruenta de la chanza, es un acierto restar solemnidad al aprendizaje. Son numerosas las virtudes que se obtienen al reforzar con medios lúdicos la docencia de la paleografía, y de su pariente la epigrafía, dicho sea de paso (Zozaya, 2013; Zozaya, 2014).

\subsection{Interactive album of mediaeval palaeography / Album interactif de paléographie médiévale}

Este álbum interactivo de paleografía medieval (siglos IX al XV) está coordinado por Marjorie Burghart (Ehess, Ciham). Además de ocuparse de elaborar numerosos ejercicios de transcripción, tiene méritos digitales: es la artífice del sitio web y del $\mathrm{XML} / \mathrm{TEI}$ del curso. Según se explicó anteriormente, este álbum usa el software libre Paleography que permite reproducir el mismo modelo de curso digital (véase el epígrafe 3.7).

El álbum se presenta en francés e inglés, pero ofrece facsímiles en francés, latín e italiano. Permite elegir el ejercicio de transcripción según las centurias, la lengua o la dificultad de lectura, para aprender gradualmente (en la columna de la izquierda).

Elegido un facsímil (figura 13), al situar el cursor sobre una letra surge un marco rectangular que enmarca la palabra a la que pertenece la letra señalada. Para ampliar la imagen (en zoom) sólo hay que hacer clic en dicho rectángulo. Abajo hay casillas para transcribir palabra por palabra (no letra por letra), que se colorearán de verde si la lectura es correcta, o de rojo si es incorrecta. Más abajo se lee la transcripción.

\subsection{Exercices de paléographie avec les comptes des Chatellenies Savo- yardes}

Estos ejercicios (figura 14) son en esencia iguales a los vistos en el apartado 3.6. Su similitud se debe a que también usa el mismo software libre de edición animada de facsímiles ya comentado. En particular, sus presentes ejercicios versan sobre documentos contables de Saboya.

\subsection{Theleme (Techniques pour I'historien en ligne)}

La École nationale des chartes (ENC), dependiente de la Université Paris-Sorbonne, ofrece el curso Theleme con ejercicios interactivos de transcripción. Destaca especialmente la sección de facsímiles interactivos. Adentrándose en sus carpetas (en dossiers documentaires), se hallarán los ejercicios telemáticos (en fac-similé interactif). Su virtud, ya vista en otros casos, radica en que al colocar el cursor encima de una letra aparece la transcripción del renglón completo (figura 15), aunque no de la letra.

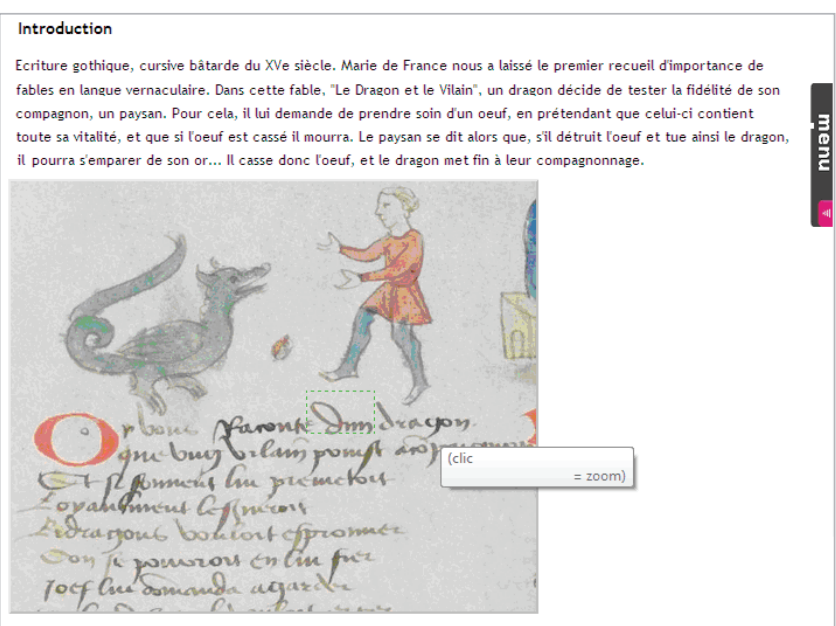

Figura 13. Ejercicio del Interactive album of mediaeval palaeography. http://ciham.ish-lyon.cnrs.fr/paleographie/exo.php?id=gothique_15e fable\&l=en

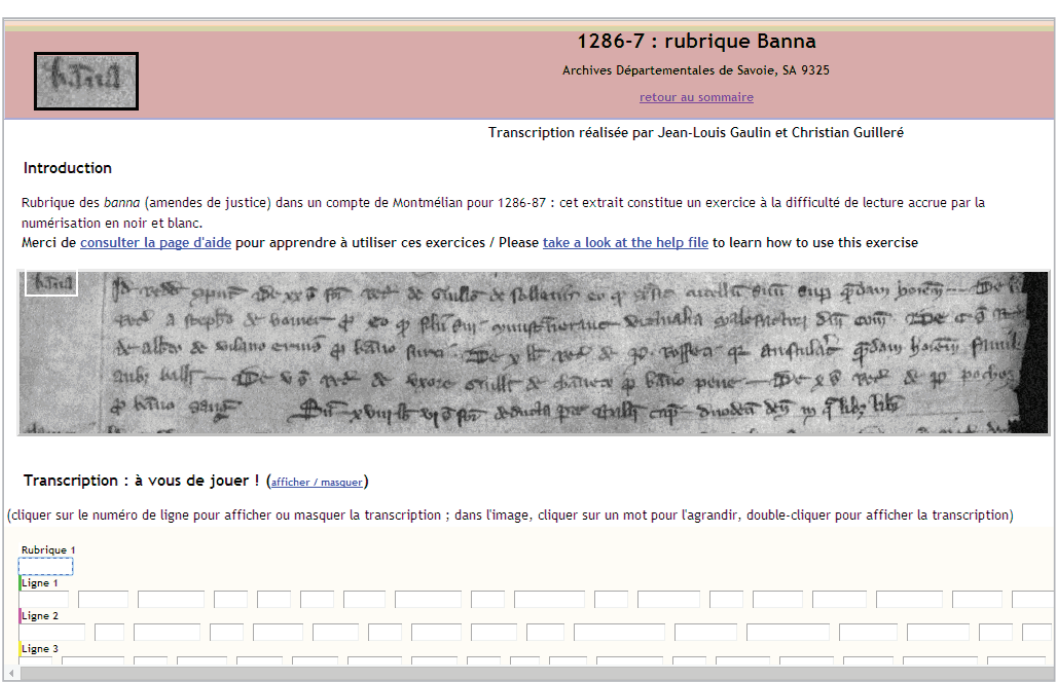

Figura 14: Ampliación de la imagen de una palabra (parte superior izquierda). http://paleographie.castellanie.net

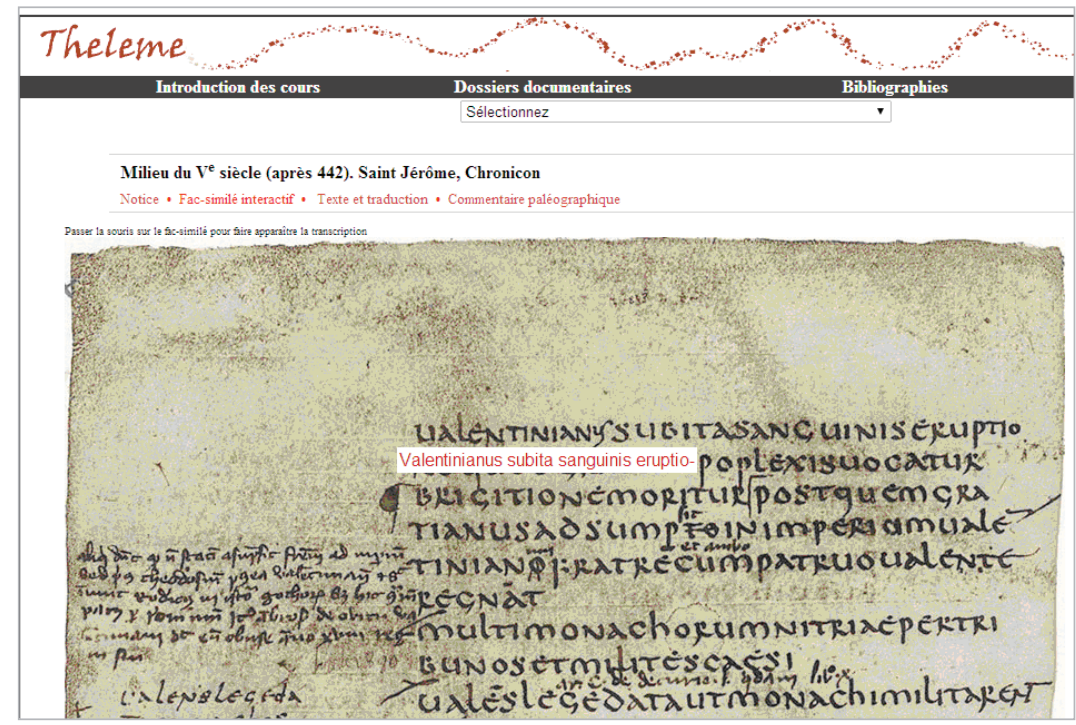

Figura 15: Transcripción del primer renglón de un facsímil del curso Theleme http://theleme.enc.sorbonne.fr/dossiers/vue1.php 
Exercici de desenvolupament d'abreviatures Ejercicio de desarrollo de abreviaturas

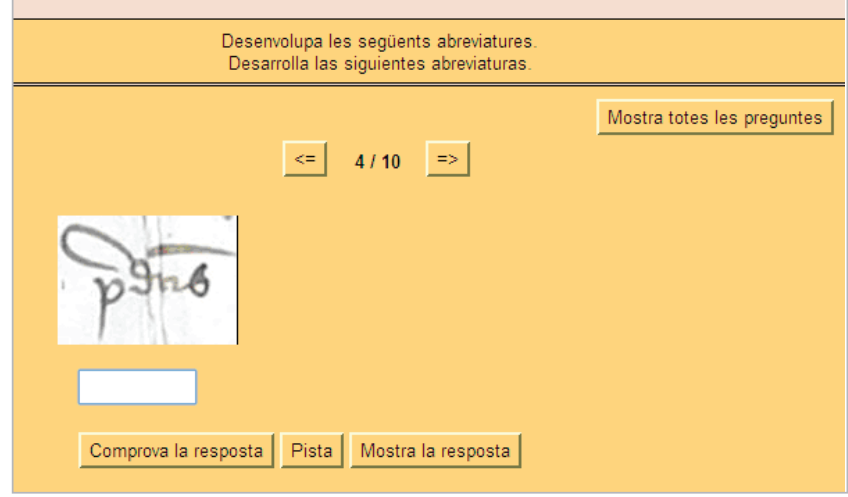

Figura 16: ejercicio de desarrollo de abreviaturas en el curso de Scriptorium http://www.ub.edu/contrataedium/scriptorium/exercisis/abreviatures/ abreviat_4/abrev_4.htm

Incluye material complementario muy interesante, pero similar al ya comentado en otros métodos. En este sentido, incluye un diccionario de abreviaturas. Huelga comentar que ya eran de sobra conocidos este tipo de repertorios, que actualmente se hallan reproducidos en internet. Es el caso del diccionario de Capelli, publicado por primera vez en 1912 y actualmente digitalizado.

\subsection{Scriptorium}

La Universidad de Barcelona más el grupo Taedium han publicado un curso en internet muy útil. Por ahora es el único programa informático español dedicado al aprendizaje de la paleografía. Cuenta con varios méritos. Entre otros, incluye numerosos ejercicios de autocorrección (en exercicis autocorrectius) relativos a las abreviaturas, la cronología, la transcripción y los instrumentos de descripción (en los que se vale de la herramienta Hot potatoes, ya citada). Por ejemplo, en un ejercicio concerniente a las abreviaturas (figura 16), si el aprendiz no sabe qué poner, el test da pistas, e incluso puede desvelar la respuesta, para enseñar con la técnica del ensayo-error. Su apariencia presenta cierto talante lúdico. Es un acierto aplicar juegos para reforzar el aprendizaje, como ya se dijo.

Destaca por su inmediatez el apartado del facsímil interactivo (en l'anàlisi documental), aunque por ahora cuenta sólo con dos documentos medievales en latín. Ofrecen la transcripción del renglón completo con tan sólo colocar el cursor sobre alguna letra (figura 17), igual que sucedía en otros cursos. Además adjuntan materiales de apoyo a la docencia ya conocidos. Por ejemplo, una colección de facsímiles con su correspondiente transcripción en pdf. También cuenta con materiales docentes expuestos de forma muy didáctica.

\section{Conclusiones}

Para apreciar los logros de los cursos interactivos de paleografía con fines docentes no basta con mirar al presente. Es necesario enfocar al pasado para comprender qué se ha heredado del sistema tradicional. Dado que este balance se ha ido ofreciendo a lo largo del artículo, es oportuno establecer conclusiones sobre las ventajas y las desventajas de los sistemas propios de la era digital.



Figura 17: Facsímil interactivo y transcripción del primer renglón (Scriptorium)

http://www.ub.edu/contrataedium/scriptorium/facsimils/coleccio\%20 facsimils/dotalia/interactif.htm

Entre las ventajas del sistema digital, el formato para ver el facsímil a todo color resulta muy atractivo. Supera a la monotonía de los manuales, con sus típicas láminas en blanco y negro. También es más ventajoso ver un facsímil en una pantalla, pues permite ampliar la imagen y apreciar detalles con gran calidad. Esto evidencia lo aparatosa que era la lupa de formato clásico. Además, se puede aventurar que los cursos del futuro ofrecerán calidades y posibilidades tan sorprendentes como las resultantes de la aplicación tridimensional del mapamundi de la catedral de Hereford (en 3DScan).

Entre las ventajas del sistema digital destacan el color y la posibilidad de ampliar la imagen y apreciar detalles con gran calidad

¿En qué radica el mayor mérito de los cursos interactivos de paleografía digital? Posiblemente, en la rapidez de la respuesta. Así supera la sensación de estatismo de los manuales tradicionales, donde era normal que el cansancio provocase perderse de renglón. Esto el ordenador lo soluciona con el simple cursor.

Acaso una de las mayores ventajas de los ejercicios interactivos de paleografía se evidencia cuando, al situar el cursor sobre alguna grafía del facsímil, aparece una transcripción al instante. Este ingenio rápido y práctico muestra que se ha sacado rendimiento al lenguaje digital, aportando nuevas técnicas de enseñanza. Para perfeccionarlo sólo haría falta que el sistema transcribiese por separado las letras, no en bloques de palabras o renglones. Compensaría, aunque requiriese un trabajo ímprobo previo para elaborar los mapas conceptuales informáticos.

Además, todos los cursos interactivos se alimentan de algunas ventajas comunes al medio digital. Por ejemplo, de las bondades de digitalizar documentación y ponerla en libre acceso. Entre otras cosas, favorecen la divulgación científica y ahorran tiempo, gastos y desplazamientos al investigador (Zozaya, 2012a, pp. 119-120).

Otra ventaja general del formato digital es su comodidad y su versatilidad. Un mismo aparato (ordenador, tableta, telé- 
fono) permite acceder in situ a multitud de cursos interactivos. A ello se suma su capacidad de incorporar nuevos cursos y ejercicios al instante de ser publicados en internet. Por añadidura, como parece que en el formato online el saber no ocupa lugar, la mayoría de las propuestas suman materiales docentes, así que acostumbran a ser muy completas.

Hay un beneficio general que se liga a la introducción de las TIC en la docencia. Los sistemas se han volcado en facilitar el aprendizaje. Para ello se percibe una tendencia generalizada a simplificar el discurso (Zozaya, 2012c). Además se está tendiendo a vincular el aprendizaje con lo lúdico (gamification o ludificación). Comienza a estar bien visto complementar la docencia universitaria con juegos. En el otro polo, lo digital también cuenta con algunas desventajas (Pons, 2006, pp. 113-114, 116, 129-130; Ramírez-Sánchez, 2005b, pp. 834835). Sin embargo, apenas afectan a la docencia de la paleografía elemental. Incluso, un problema tan abundante en internet como la saturación de información sin cotejar científicamente (Zozaya, 2009, pp. 240-241) no se manifiesta en estos cursos, pues están respaldados académicamente.

Parece que sólo podría hallarse alguna desventaja en los cursos de paleografía digital si se examinasen puntillosamente. La pega atañe a la evaluación. Los cursos acostumbran a incluir ejercicios de autocorrección. Para que el programa refleje la opción "correcta" hay que incluirla previamente, y no siempre es fácil hallar la transcripción perfecta. Stokes (2010, p. 240) ha incidido en el problema de lo subjetivas que resultan algunas decisiones al transcribir un texto. Si existe más de una interpretación ante una cuestión gráfica ambigua, el ordenador ofrecerá una respuesta automática, y si evalúa negativamente la respuesta del alumno, se estará cercenando la famosa retroalimentación (feedback) tan aclamada del sistema digital. Es cierto que lo mismo puede suceder en los manuales, pero la docencia presencial sí permite -en teoríaque un profesor escuche y sea flexible. Relacionado con ello cabría plantear el problema presente en algunos manuales: las erratas en la transcripción. Igualmente, sería comprensible que los cursos digitales incluyesen algún dislate.

\section{La digitalización de la documentación y su puesta en libre acceso favorecen la divulgación científica y ahorran tiempo, gastos y desplazamientos al investigador}

Stokes (2010, pp. 240-241) ha planteado si el sistema digital puede suplantar a la docencia presencial, y concluye que no. Personalmente, opino que, en vez de pensar en exclusión, hay que pensar en complementariedad y enriquecimiento mutuo. Hasta ahora el sistema telemático se ha nutrido sustancialmente del método anterior, así que posiblemente llegue el proceso simbiótico inverso en un futuro.

A modo de colofón acabaré con un lamento y una propuesta. Lamento que no existan cursos de paleografía digital en español, una de las lenguas más habladas del mundo. Es sorprendente, además, dada la riqueza de nuestros archivos históricos, sumada a la ingente cantidad de documentación digitalizada que tenemos. Actualmente sería relativamente fácil cubrir ese vacío, gracias al software libre denominado Paleography ya citado, creado para editar facsímiles interactivos con fines docentes. Para ello, propongo juntar a un grupo de paleógrafos más algún programador informático. Muchas personas estaríamos encantadas de participar en esa empresa tan apasionante.

Actualmente es factible preparar un curso de paleografía española con el software libre Paleography, supliendo así una gran carencia

\section{Bibliografía}

Arribas, Filemón (1965). Paleografía documental hispánica. V. II: transcripciones. Valladolid, Sever-Cuesta.

Capelli, Adriano (1899). Dizionario di abbreviature latini ed italiani. Ed. Ulrico Hoepli, Milán (reed. de 1912). http://www.hist.msu.ru/Departments/Medieval/Cappelli

Cortés-Alonso, Vicenta (1986). La escritura y lo escrito: paleografía y diplomática de España y América en los siglos XVI-XVII. Madrid: Instituto de Cooperación Iberoamericana. ISBN: 8472323935

Delgado-Aguiar, Gerardo; Martín-Rodríguez, Ernesto; Ramírez-Sánchez, Manuel (2005). "Pretérito imperfecto y futuro indefinido. Las TIC en la docencia universitaria de la Facultad de Geografía e Historia de la Ulpgc". En: Rodríguez-Díaz, Jorge M.; Castro-Sánchez, José-Juan (coords.). Las tecnologías de la información y comunicación (TIC) en la docencia universitaria. Actas de las II Jornadas canarias sobre las tecnologías de la información y comunicación en la docencia universitaria (Las Palmas de Gran Canaria, diciembre de 2004). Servicio de Publicaciones de la Universidad de la Palmas de Gran Canaria, pp. 265-277. ISBN: 8496502392

http://www.personales.ulpgc.es/mramirez.dch/downloads/99. $p d f$

Millares-Carlo, Agustín (1983). Tratado de paleografía española. 3 v., 3a ed. Madrid: Espasa Calpe. ISBN: 8423949869

Pérez-Herrero, Enrique; Rivero-Suárez, Benedicta (2006). Escritura manuscrita y letra procesal (Canarias en el siglo XVI). Las Palmas de Gran Canaria. ISBN 13: 9788496577329

Pons, Anaclet (2006). "La historia maleable. A propósito de internet". Hispania, revista española de historia, v. 66, n. 222, enero-abril, pp. 109-130.

http://hispania.revistas.csic.es/index.php/hispania/article/ viewArticle/4

http://dx.doi.org/10.3989/hispania.2006.v66.i222.4

Ramírez-Sánchez, Manuel (2005a). "La utilización de las nuevas tecnologías en la docencia universitaria de la paleografía, diplomática, epigrafía y numismática". En: Rodríguez-Díaz, Jorge M.; Castro-Sánchez, José-Juan (coords.). Las tecnologías de la información y comunicación (TIC) en la docencia universitaria. Actas de las II Jornadas Canarias sobre las Tecnologías de la Información y Comunicación en la docencia universitaria, Las Palmas de Gran Canaria, diciem- 
bre de 2004. Servicio de Publicaciones de la Universidad de la Palmas de Gran Canaria, pp. 279-288. ISBN: 8496502392 http://www.personales.ulpgc.es/mramirez.dch/downloads/98. $p d f$

Ramírez-Sánchez, Manuel (2005b). “Las tecnologías de la información y de la comunicación aplicadas a la docencia universitaria en Epigrafía y Numismática: presente y futuro". En: Alvar, Antonio; González, José-Francisco (eds.). Actas del XI Congreso español de estudios clásicos, Santiago de Compostela, 15-20 sept. 2003, v. III. Madrid: Sociedad Española de Estudios Clásicos, pp. 831-841. ISBN: 8468938939 http://www.cervantesvirtual.com/servlet/SirveObras/ antig/01593063103363851881146/index.htm http://www.personales.ulpgc.es/mramirez.dch/downloads/122. $p d f$

Riesco-Terrero, Ángel; Ruiz-García, Elisa; Domínguez-Aparicio, Jesús; Sánchez-Prieto, Ana B. (1995). Aproximación a la cultura escrita: material de apoyo. Madrid: Ed. Playor. ISBN: 8435907205

Sánchez-Prieto, Ana B. (2010). "Aprender a leer y escribir antes del año mil". Estudios sobre educación, v. 18, junio, pp. 59-81. http://dspace.unav.es/dspace/bitstream/10171/9820/3/ ESE_18_3.pdf

Stokes, Peter A. (2010). "Teaching manuscripts in the digital age". En: Fischer, Franz; Fritze, Christiane; Vogeler, Georg (eds.). Codicology and palaeography in the digital age. Norderstedt, BoD, pp. 229-245. ISBN: 9783842350328 http://kups.ub.uni-koeln.de/4352

Uned (2005). Paleografía y diplomática, v. I. 12ª ed. Madrid. ISBN v. 1: 8436220536

Zozaya, Leonor (2009). "El desarrollo de competencias en historia y ciencias y técnicas historiográficas a través de un espacio virtual en internet". Relada (Revista electrónica de ADA), v. 3, n. 3, pp. 240-248.

http://polired.upm.es/index.php/relada/article/view/83/83

Zozaya, Leonor (2012a). “Difusión de documentación primaria digitalizada como arma de doble filo en la historia. Un ensayo futurista". MEl, Métodos de información, v. 3, n. 4, pp. 117-125.

http://www.metodosdeinformacion.es/mei/index.php/mei/ article/viewFile/IIMEI2-N2-117125/757

http://dx.doi.org/10.5557/IIMEI2-N2-117125

Zozaya, Leonor (2012b). "La aplicación de técnicas informáticas con fines docentes para un manual de paleografía". En: Munita, José A.; Lema, José A. (eds.). La escritura de la memoria. Libros para la administración. Vitoria: Universidad del País Vasco, pp. 365-370. ISBN: 9788498607222

Zozaya, Leonor (2012c). "La sencillez en el discurso docente para facilitar el aprendizaje". En: Actas del IV Encuentro de innovación educativa. Madrid, Universidad Complutense de Madrid, 18-19 abril 2012, (en prensa).

Zozaya, Leonor (2013). "Alternativas lúdicas en internet para reforzar la docencia de paleografía". En: Aprender con tecnologías digitales. Actas del Congreso Ciamte 2013: Congreso iberoameri- cano de aprendizaje mediado por la tecnología. México, Universidad Nacional Autónoma de México, 26-30 agosto 2013.

Zozaya, Leonor (2014). "Epiteca: una ludoteca virtual para reforzar conocimientos de epigrafía latina". En: Lavado, Pedro J.; Lacambra, Víctor M. (eds.). VII Jornadas de ludotecas de la comarca de la sierra de Albarracín. Juegos romanos y juegos de agua, 19-21 julio 2013). Ponencias y comunicaciones. Albarracín: Ed. Comarca de la Sierra de Albarracín, pp. 155-170. ISBN: 9788469704899

\section{Sitios de interés}

Conscriptio. El blog de las ciencias y técnicas historiográficas http://conscriptio.blogspot.com.es/2011/09/recursosonline-para-el-aprendizaje-de.html

Cours d'initiation à la paléographie médiévale et moderne http://www.uoh.fr/front/notice?id=6775834b-95b4-4ed4bc26-082e145476fa

English handwriting, 1500-1700. An online course http://www.english.cam.ac.uk/ceres/ehoc/index.html

Exercices de paléographie avec les comptes des Chatellenies Savoyardes

http://paleographie.castellanie.net

Interactive album of mediaeval palaeography / Album interactif de paléographie médiévale

http://ciham.ish-lyon.cnrs.fr/paleographie/index.php?/=en

International conference on frontiers in handwriting recognition http://www.informatik.uni-trier.de/ /ey/db/conf/icfhr/index.html

Latin palaeography (The National Archives, England) http://www.nationalarchives.gov.uk/records/reading-olddocuments.htm

Mapamundi of Hereford cathedral http://www.themappamundi.co.uk/explore.php

Medieval writing http://medievalwriting.50megs.com/writing.htm

Palaeography (The National Archives, England) http://www.nationalarchives.gov.uk/palaeography

Paleography (free software \& instructions) / Paléographie (logiciel libre et instructions).

http://tapor.uvic.ca/ mholmes/image_markup/paleography.php

Paleografía y ciencias afines

http://paleografia.hypotheses.org

Scottish handwriting.com

http://www.scottishhandwriting.com/coach.asp

Script tutorials. Resources for old handwritings and documents https://script.byu.edu/Pages/home.aspx

Scriptorium

http://www.ub.edu/contrataedium/scriptorium.htm

Spanish paleography. Digital teaching \& learning tool http://spanishpaleographytool.org

Theleme. Techniques pour l'historien en ligne http://theleme.enc.sorbonne.fr 